\title{
Grain growth inhibitors in cemented carbide application
}

\author{
Aimin Jiang ${ }^{\mathrm{a}}$, Bo $\mathrm{Wen}^{\mathrm{a}}{ }^{\text {, weibo } Z \mathrm{Zhu}^{\mathrm{a}}}$ \\ Chongqing Academy of Science \&Technology, China \\ a44290159@qq.com
}

Keywords:cemented carbide; grain growth inhibitors; metal carbide; rare earth element.

\begin{abstract}
The crystal grain of the cemented carbides can occurs in the process of sinteing of cemented carbides. Relational researches prove that appended inhibitors can prevent the growing of crystals in cemented carbides effectively. In recent years, appended Inhibitors in cemented carbides are studied at home and abroad. The inhibiting mechanism of the crystal grain growth inhibitor in cemented carbides and their methods to dope, and influencing factor on the inhibitory effect of the crystal grain growth inhibitor were summarized in this paper. Meanwhile, Transited metal carbides , Rare earth, Sulfur and Phosphorus, Copper and Molybdenum which were used crystal grain growth inhibitors and their effect on the prosperities of the alloy are introduced .Finally introduced the crystal growth inhibitor compound increase, the new the preparation, the new development of inhibitor.
\end{abstract}

\section{Introduction}

WC-Co cemented carbides are metal-ceramic composites consisting of a ceramic phase, tungsten carbide, and a cobalt binder. They are broadly used in various industrial applications and almost in each household, for example, as masonry drill bits, due to their unique combination of high hardness, wear-resistance, toughness and strength. Since their discovery in Germany in the 1920s, WC-Co cemented carbides did not dramatically change. With the rapid developing of industry, cemented carbides are required higher and higher. In particular, cemented carbides with smaller WC grain sizes provide tools with superior surface precision and longer life, which result in a higher precision for micro-components such as microprobes for large-scale integration (LSI) applications, inkjet nozzles, and optical fiber multi connectors.

The results are as following ${ }^{[1]}$ : when the WC cemented carbide grain under 0.5 microns, the finer the grain size of WC, the less defect in alloy and the higher their strength and hardness. The size of WC powder used in the production of ultra-fine cemented carbides is much smaller than that of the general cemented carbide. The surface activation energy of the WC powder is high, and the grain growth is easily caused by the sintering process. The grain growth is one of the crack sources.

At present, there are two main methods of controlling grain size: firstly, the new sintering equipment, the results ${ }^{[2]}$ showed that the densification of the alloy had accomplished within 30 s at $1400{ }^{\circ} \mathrm{C}$, the grain size is $0.2 \mu \mathrm{m}$, but if the sintering time is extended to $60 \mathrm{~s}$, the grain size is rapidly growing up to $2 \mu \mathrm{m}$. There are some sintering process can be used to sintering nano WC-Co hard alloy composite powder, such as microwave sintering, hot pressing sintering, spark plasma sintering and the two stage sintering process. Secondly, grain growth inhibitors to inhibit the growth of the grain, such as TaC, VC and Cr3C2.This thesis mainly introduces the inhibition mechanism of grain growth inhibitors, the method of adding the inhibitor, the commonly used inhibitors, and the effect of the inhibitor on the comprehensive properties of the alloy.

\section{2. mechanisms of inhibitors}

During sintering the average grain size increases due to coarsening, where large grains grow and small grains dissolve. The WC grains have a faceted shape and therefore have a strong tendency for abnormal grain growth (AGG), where a few large grains grow much larger than the average. The addition of inhibitor has slowed speed of dissolution and precipitation of WC. There are three inhibition mechanisms. First, on the basis of the theory of crystal growth; Hayashi suggested a mechanism in which WC grain growth is inhibited by dopant adsorption at steps/kinks on the WC 
grain surface during liquid-state sintering ${ }^{[3]}$. It is because that W atom cannot precipitate at a step/ kink on the WC surface when dopant atom adsorbs at the step/kink. Second, on the basis of high-resolution transmission electron microscopy (HRTEM) observations and X-ray microanalysis (XMA) spectroscopy. Egami ${ }^{[4]}$ reported a mechanism in which the grain growth of WC is inhibited by VC through a decrease in the motive force for the construction of WC from liquid Co (actually, the $\mathrm{Co}-\mathrm{W}-\mathrm{V}-\mathrm{C}$ solution) due to the prior segregation of $\mathrm{V}$ compounds at WC/Co interfaces during cooling. Several subsequent papers have also been published on this topic.

\section{Factors affecting of the inhibitors}

The effect of inhibitor was determined by the following factors: (1) the particle size of powder: Reducing the particle size of WC powder can increase the surface area of WC; inhibitors can be distributed on the surface of WC and increase the effect. (2) Cobalt content: at a certain temperature, when cobalt content decreased, the mean free path was declined, and the effect of the inhibitor is easy to play. (3) The uniformity of powder: The distribution contours of inhibitors are inhomogeneous, which will increase the diffusion distance. (4) Alloy sintering temperature: The increase of the sintering temperature increases the amount of liquid phase, which is required to increase the concentration of the inhibitor in the liquid phase.

\section{4. types of grain growth inhibitors}

\subsection{Transition-metal carbides}

Transition metal carbides are the common grain growth inhibitors. The effect of transition metal carbides is related to its thermodynamic stability ${ }^{[5]}$. The order of their thermodynamic stability is: VC $>$ Cr3C2 $>$ TaC $>$ TiC $>$ ZrC $>$ NbC $>$ HfC. However, each kind of carbide has a maximum number of additions that can be adde. At a certain temperature, the amount of carbide additive is determined by the saturation concentration of the carbide in the binder phase and the content of the bonded phase.

Table 1: the solubility of different additives in the cobalt phase [5]

\begin{tabular}{ccc}
\hline inhibitors & the eutectic temperature of MexCy-Co $\left({ }^{\circ} \mathrm{C}\right)$ & $\begin{array}{c}\text { Solubility of mexCy in cobalt phase at } 1400^{\circ} \mathrm{C} \\
(\mathrm{mol} \%)\end{array}$ \\
\hline $\mathrm{TiC}$ & 1360 & 1.5 \\
$\mathrm{ZrC}$ & 1360 & 6 \\
$\mathrm{HfC}$ & 1370 & 3 \\
$\mathrm{VC}$ & 1330 & 10 \\
$\mathrm{NbC}$ & 1380 & 6 \\
$\mathrm{TaC}$ & 1370 & 3 \\
$\mathrm{Cr}_{3} \mathrm{C}_{2}$ & 1245 & 12 \\
\hline
\end{tabular}

The inhibition effect of VC on the grain growth of WC was mainly determined by the ratio of $\mathrm{VC} / \mathrm{Co}$, and the infiltration process of the inhibitors was mainly through the diffusion of the bonded phase and the Co - WC interface. Both V and Co were segregated at WC (0001)/WC(0001) or WC(0001)/WC(randomly oriented plane) interfaces and were slightly segregated at WC(10 0)/WC(10 0) or WC(10 0)/WC(randomly oriented plane) interfaces. The V concentration depended on the WC crystallographic orientation, whereas the Co concentration had a small correlation. When Co is spread on the surface of WC, VC spontaneously adsorbed on WC particles through liquid bonding. The contact area of WC and liquid is reduced, the dissolution rate of WC particles is decreased, and the saturated solubility of WC particles is reduced. Although the transition metal carbide inhibitor can effectively inhibit the growth of WC grains, these materials often cause the increase of the porosity, which leads to the deterioration of the material properties.

$\mathrm{Cr}_{3} \mathrm{C}_{2}$ grain growth inhibitors are situated between WC crystal and solid solute in Co, In the WC/Co phase interface, $\mathrm{Cr}_{3} \mathrm{C}_{2}$ was not found. The Cr may form an adsorbed layer on the surface of WC, which prevents the WC from dissolving in the liquid phase; thereby preventing the WC grains grow up by the liquid phase recrystallization, which makes the grain size of WC thin. The large $\mathrm{Cr}$ 
solubility in the liquid binder leads to assume that this phase precipitates on cooling. The modification by $\mathrm{Cr}$ of the morphology and of the growth process of the WC grains leads to deduce that $\mathrm{Cr}$ segregates in the binder at the WC interface at sintering temperature. This Cr enrichment in the interface film and the low interface energy induce the preferred nucleation of $(\mathrm{Cr}, \mathrm{W}) \mathrm{C}$ on the WC planes on cooling ${ }^{[6]}$.

\section{2 rare earth elements}

The rare-earth doped cemented carbides have being investigated and developed for mass production. Many researches ${ }^{[7-9]}$ on doped compositions and contents, addition approaches, processing scheme, strengthening mechanism, microstructure and mechanical properties of rare-earth doped cemented carbides have been done according to the processing techniques. The current trends on strengthening mechanisms of rare-earth doped cemented carbides could be that the solid solution contents of (W,Ti)C or WC in Co binder are slightly increased, and the addition of rare-earth can increase the contents of $\alpha$-Co binder with fcc structure, and the addition of rare-earth could slightly decrease the grain sizes of WC/Co alloys.

\section{Methods of addition grain growth inhibitors}

There are three ways to add the inhibitor ${ }^{[10]}$. First, The WC, Co and grain growth inhibitor are added into the ball mill. this method is a commonly method, But the grain growth inhibitors are difficult to mixing Uniformly, and it is difficult to controlling the growth of WC grains; second, In the process of preparation of tungsten carbide, the corresponding oxide of the grain growth inhibitor is added. Third, the salt solution of the grain growth inhibitor is mixed with the blue tungsten wet. The coating powder of the blue tungsten is formed first, then the Co wet grinding, which is a kind of ideal adding method, but the process is complex, and it is difficult to operate.

\section{Effect on the properties of the metals}

The effects of grain growth inhibitors on the properties of the alloys are mainly reflected in the aspects of the hardness and bending strength of the alloy. Different additives can inhibit the growth of the grain size, so the effect of different grain growth inhibitors on the properties is not the same.

\section{1 transition metal carbides effect on properties of alloy}

Johannes Poetschke ${ }^{[11]}$ studies show that. Samples with an ultrafine microstructure free of abnormal grain growth, a hardness of $25.5 \mathrm{GPa}$ and a fracture toughness of $7.2 \mathrm{MPa} \cdot \mathrm{m} 1 / 2 \mathrm{were}$ archived by conventional sintering. Both carbides reduce grain growth, but with $\mathrm{Cr} 3 \mathrm{C} 2 \mathrm{a}$ finer microstructure can be achieved at lower amounts. Compared to the same amount of $\mathrm{Cr}_{3} \mathrm{C}_{2}$, the addition of VC results in smaller grains but lower hardness and fracture toughness. Results ${ }^{[1]}$ show that the synergistic action of doped $\mathrm{VC} / \mathrm{Cr}_{3} \mathrm{C}_{2}$ in optimal proportion enhances both the hardness and transverse rupture strength (TRS) of the alloys, with more homogeneous microstructure. When the alloy is sintered at $1430+\mathrm{C}$ and with $0.5 \% \mathrm{Cr} 3 \mathrm{C} 2 / 0.2 \% \mathrm{VC}$, the TRS reaches $3786 \mathrm{MPa}$, the hardness is $91.7 \mathrm{HRA}$ and the grain size smaller than $0.6 \mu \mathrm{m}$.

\subsection{Rare earth elements Effect on the properties of the alloy}

Luo Zhonglin ${ }^{[12]}$ show that raising of the macro-pressure stress on WC-8Co alloy sample surface by the rare earths is the important strengthening factor, the effect of stopping $\mathrm{fcc} \rightarrow$ hcp transformation of $\gamma$-phase on raising the alloy strength by adding rare earths is very little. There are no significant effect of the rare earths on the alloy microstructure parameters and no additional strengthen effect of W solute on $\gamma$-phase. Sun Jing ${ }^{[13]}$ shows that the bending strength of the alloy is improved in some extent when the proper rare-earth is added. The maximum increasing range is $5.8 \%$. The hardness is also improved (0.5 2 HRA) at the same time.

\section{Conclusion}

Ultra-fine grain cemented carbide has unique performance; it has wide application field and broad market prospect. Performance of Ultra-fine grain cemented carbide based on adding inhibitors is 
better than that of using new sintering method. Some new additives, process technique and new sintering equipment's are key factors in the improvement of properties of cemented carbide. In recent years, appended Inhibitors in ultra-fine cemented carbides are studied at home and abroad. Now the researches of additives are mainly vibration refractory metal carbides 。

\section{Acknowledgements}

The authors are grateful to Chongqing Academy of Science \&Technology for supplying of materials and testing of samples .the research work in this paper was supported by Natural Science Foundation Project of CQ CSTC(NO.CSTC2012jjA50030) and Basic scientific research business in Chongqing(2015cstc-jbky-00104)

\section{References}

[1] Yiwen LEI, Jing SUN, Xiwen DU, Qi ZHAI. Properties and microstructure of VC/Cr3C2-doped WC/Co cemented carbides. RareMetals, 2007, 26(6):584-590

[2] Xiaodong Li, Xingqing Wang, Yingfang Jie, etal. Development of nanocrystalline cemented carbide [J]. Shanghai metal, 2004, 26 (3): 52-56.

[3] Choi.k, Hwang N M and kim D Y.Effect of VC addition on microstuctural evolution of WC-Co alloy: mechanism of grain growth inhibition. powder Metallurgy,2000,43(2):168-171.

[4] Jia Zuocheng. Development of ultra - fine grained cemented carbide . cemented carbide, 2000, 17 (1): 58-63.

[5] Guo Gengchen. Liquid phase sintering powder metallurgical materials. Chemical Industry Press.2002:22 - 27

[6] A.Delanoe,M.Bacia,E.Pauty,S.Lay,C.H.Allibert. Cr - rich layer atthe WC/Co interface in $\mathrm{Cr}-$ doped WC-Co cermens: segregation ormetastable carbide .Journal of Crystal Growth .2004,270:219-22

[7]L. Sha.Study on rare-earth doped cemented carbides in China.Int. J. Refract. Met. Hard Mater., 27

(3) (2009: 528-534

[8]S. Liu, Z.-L. Huang, G. Liu, G.-B. Yang. Preparing nano-crystalline rare earth doped WC/Co powder by high energy ball milling.Int. J. Refract. Met. Hard Mater., 24 (6) (2006):461-464

[9]L. Zhang, S. Chen, Q. Nan, M.-w. Xie, H.-p. Wu, Y.-p. Feng. Effect of La containing phases on microscopic wear characteristics and residual stress of WC-Co cemented carbide.Int. J. Refract. Met. Hard Mater., 41 (2013):7-11

[10] Lei Yiwen. Effect of grain growth inhibitor on the properties of ultrafine cemented carbides [D], 2003, Central South University

[11] Johannes Poetschke, Volkmar Richter, Roland Holke. Influence and effectivity of VC and Cr3C2 grain growth inhibitors on sintering of binderless tungsten carbide.International Journal of Refractory Metals and Hard Materials. 2012,31:218-223

[12]Luo Zhonglin. Study on the effect of rare earth elements on the properties of cemented carbides [J]. cemented carbides, 1991, (2): 12-19.

[13] Sun Jing, Wang Bo et al. Research on $\mathrm{Fe} /(\mathrm{Co} / \mathrm{Ni}$ WC-20) cemented carbide by adding rare earth [J]. powder metallurgy technology, 1998,16 (4): 267 - 265 